\title{
Gestão de Frotas na construção civil: inovação, proposta de valor e impactos nas relações cliente-empresa
}

Fleet management in the civil construction sector: innovation, value proposition and impacts on customer-company relationship

\author{
Marcelo Soares do Nascimento ${ }^{1^{*}}$, Renata Maria Christofoleti-Furlan² \\ ${ }^{1}$ Hilti do Brasil - Gerente de Contas Chave - Av. Ceci, 426 - Tamboré - CEP 06460-120 - Barueri (SP), \\ Brasil \\ 2 Pecege - Doutora em Ciências - Rua Alexandre Herculano, 120 - Vila Monteiro - CEP 13418-445 - \\ Piracicaba (SP), Brasil
}

\section{Resumo}

Empresas têm buscado soluções inovadoras que venham a agregar valor e que possam contribuir com o seu desenvolvimento. Neste cenário, uma empresa do setor de construção civil desenvolveu o serviço Gestão de Frotas, que oferece aos clientes ferramentas novas e atualizadas com um custo mensal fixo, funcionando como uma locação, porém com diferenciais significativos que o distingue dos demais. O objetivo do trabalho foi analisar a criação do serviço Gestão de Frotas e sua respectiva proposta de valor, bem como os impactos de sua implementação nas relações com o cliente e os benefícios gerados para a empresa. Empregou-se como metodologia o estudo de caso único. Os dados foram levantados junto aos principais departamentos da empresa e a análise baseou-se em relatórios internos e entrevistas não estruturadas. O levantamento dos pontos críticos junto ao segmento da construção civil, destacando-se a falta de preocupação com o parque de ferramentas, bem como o desconhecimento dos custos reais envolvidos na aquisição e manutenção do mesmo, levou a empresa a identificar que o pagamento pelo uso e não pela propriedade da ferramenta seria mais eficiente para os clientes. A criação do serviço e sua proposta de valor se basearam na oferta de serviços e não na venda de produtos. O serviço estreitou e fortaleceu 0 relacionamento com os clientes e proporcionou à empresa ganhos em lucratividade, "market share" e mix de produtos, aumentando a credibilidade da marca no mercado nacional.

Palavras-chave: estudo de caso, locação, lucratividade, serviços inovadores

\begin{abstract}
Companies have been looking for innovative solutions that will add value and contribute to its development. In this scenario, a company of the civil construction sector developed the Fleet Management service, which offers customers new and updated tools with a fixed monthly cost, operating as a lease, but with significant characteristics that distinguish it from others. The objective of this work was to analyze the creation of the Fleet Management service and its respective value proposition, as well as the impacts of its implementation on the relations with the customer and the benefits generated for the company. The single case study was used as methodology. Data were collected from key departments of the company and the analysis was based on internal reports and unstructured interviews. The survey of the critical points in the construction segment, highlighting the lack of concern with the tooling as well as the lack of knowledge of the actual costs involved in the acquisition and maintenance, led the company to identify that paying for use and not for property of the tool would be more efficient for the customers. The creation of the service and its value proposition were based on the offer of services and not on the sale of products. The service tightened and strengthened the customer relationship and provided the company with gains in profitability, market share and product mix, increasing the brand's credibility in the domestic market.
\end{abstract}

Keywords: case study, lease, profitability, innovative services

\footnotetext{
*Autor correspondente <marcelobarao@hotmail.com> Enviado: 14 mar. 2017 Aprovado: 08 maio 2017
} 


\section{Introdução}

Atualmente, as empresas têm buscado, junto ao mercado, soluções inovadoras que venham a agregar valor e que também possam contribuir com o seu desenvolvimento. O dinamismo do mercado e o fortalecimento dos concorrentes têm feito com que as empresas, diariamente, procurem desenvolver e oferecer soluções inovadoras a seus parceiros, para que assim possam manter seus negócios ativos e fortalecidos frente aos desafios dos mercados de hoje. A inovação é movida pela habilidade de estabelecer relações, detectar oportunidades e tirar proveito delas (Tidd e Bessant, 2015).

A palavra inovação ganhou muita notoriedade nos últimos anos após os inventos de grandes companhias como a Apple, por exemplo, que ganhou enorme destaque por conta das frases de efeito de seu fundador citando a inovação. No entanto, segundo Drucker (2002), inovação tem um significado que vai além, referindose não apenas a realizar coisas diferentes, mas também fazendo as mesmas coisas de distintas formas, promovendo, assim, novos potenciais de satisfação.

Diante das intempéries do mercado, oferecer produtos e serviços inovadores, que propicie ao cliente uma nova perspectiva de melhoria em seus negócios, possibilita às empresas terem significativa vantagem, longevidade e liderança frente aos seus concorrentes, tornando-as mais competitivas (Pellizzoni e Fialho, 2015).

Com base no cenário da inovação, uma empresa do setor de construção civil desenvolveu um serviço inovador dentro de seu segmento de atuação denominado Gestão de Frotas. Esta empresa sempre teve seu nome muito presente no mercado industrial, petroquímico e da construção, principalmente por ser reconhecida pela inovação, desde o seu início no principado de Liechtenstein, a mais de 70 anos.

O serviço Gestão de Frotas da empresa em questão, inserido no segmento da indústria da construção civil, foi desenvolvido com o objetivo principal de fornecer aos clientes ferramentas novas e atuais, permitindo que eles possam reduzir o trabalho e os custos com gerenciamento e manutenção do parque de ferramentas, tornando-os mais produtivos e com fluxos financeiros enxutos.

O serviço busca oferecer aos seus clientes ferramentas novas e atualizadas com um custo mensal fixo, por um período que pode variar de um a quatro anos. Funciona como uma locação, porém apresenta diferenciais significativos que o distingue de uma locação comum. Com isso, o cliente tem a oportunidade de utilizar as ferramentas sem ter que arcar com o desembolso total de caixa para aquisição do produto. O serviço se diferencia dos demais ofertados pelo mercado atualmente por 
apresentar as seguintes características: a manutenção, oferecida em todo o território nacional, por conta da empresa desde a coleta da ferramenta, conserto e retorno ao mesmo local de retirada, com o custo já incluso no valor mensal pago pelo cliente, ao contrário de seus concorrentes, cujos custos com manutenção são todos por conta do contratante que assume os prejuízos derivados do uso das ferramentas; disponibilização de outra ferramenta de igual modelo pelo período em que a original estiver em manutenção; minimização de perdas no caso de furto ou roubo, evitando que o cliente arque com $100 \%$ do prejuízo.

Com estas características, o serviço busca fidelizar o cliente, levando-o a vivenciar experiências positivas e a ter um contato amplo e duradouro, buscando um relacionamento de médio e longo prazo com a empresa. Além disso, propicia que ele se preocupe com os seus negócios, ao passo que a empresa se preocupe em cuidar das ferramentas que geram tais negócios.

Do ponto de vista da empresa, a implementação do serviço Gestão de Frotas tem proporcionado uma série de benefícios relacionados à criação de valor, interações mais duradoras com o cliente, aumento da base de clientes com diferentes perfis, aumento nas vendas dos consumíveis, uso de diferentes canais de atendimento por parte dos clientes do serviço, além do aumento do faturamento da empresa.

Diante do exposto, o objetivo do trabalho foi analisar a criação do serviço Gestão de Frotas e sua respectiva proposta de valor, bem como os impactos de sua implementação nas relações com o cliente e os benefícios gerados para a empresa.

\section{Material e Métodos}

Este trabalho utilizou o estudo de caso como método científico para o seu desenvolvimento. Segundo Yin (2015), o estudo de caso é uma das várias maneiras de se realizar uma pesquisa no campo das ciências sociais, psicologia, antropologia, administração, economia, entre outros.

O estudo de caso como modalidade de pesquisa procura responder a questões que se referem ao "como" e "por que" da investigação, visando explicar alguma circunstância presente ou fenômeno (Yin, 2015). Pode englobar tanto estudos de caso único, com foco em uma unidade (indivíduo, empresa, organização, entre outros), quanto estudos de caso múltiplo, integrando várias unidades simultaneamente (vários indivíduos, várias organizações, por exemplo) (Ventura, 2007). 
O trabalho consistiu em um estudo de caso único. A unidade de pesquisa foi representada por uma empresa do setor de construção civil no que se refere ao serviço Gestão de Frotas.

\section{Descrição da unidade de pesquisa}

No âmbito global, a empresa é originária no principado de Liechtenstein. Está presente em todos os segmentos da indústria, indústria petroquímica e construção civil por mais de 70 anos, com cerca de 20.000 funcionários ao redor dos 120 países em que está presente. Uma marca de vanguarda e ganhadora de prêmios internacionais por conta dos designs e inovações de seus equipamentos, serviços e soluções.

No Brasil, a empresa localiza-se na região da grande São Paulo, possui cerca de 300 funcionários e está presente no mercado brasileiro há mais de 20 anos. Oferece soluções inovadoras para os diversos mercados da construção civil e indústria. Está presente nas principais regiões do país: Sul, Sudeste, Centro Oeste e Nordeste, onde atua com o modelo de venda direta a seus clientes.

\section{Obtenção dos dados e análise}

Os dados foram levantados a partir de relatórios internos obtidos junto aos principais departamentos da companhia: marketing, finanças e reparações. $A$ análise baseou-se nestes relatórios desde a implementação do serviço, no ano de 2010, até o ano de 2015. Também foram realizadas entrevistas não estruturadas com perguntas abertas junto aos gestores responsáveis pelo serviço, pertencentes aos mesmos departamentos já mencionados, assim como aos clientes usuários. A utilização de entrevistas não estruturadas auxilia no esclarecimento de situações, atitudes e comportamentos acerca do tema de interesse (Mattos, 2005). As entrevistas tiveram um caráter qualitativo e auxiliaram na elucidação dos dados levantados nos relatórios, de forma a facilitar a compreensão e interpretação dos aspectos relacionados à criação do serviço, bem como das estratégias empregadas e da percepção dos benefícios gerados para a companhia e para os usuários. As entrevistas serviram de apoio para o entendimento do processo como um todo, a fim de se obter informações que auxiliassem a interpretação dos resultados.

\section{Resultados e Discussão}

A inovação tem mudado a forma como muitas empresas têm se perpetuado nos mercados atuais. A inovação, seja em produtos, processos, serviços, entre outros, 
torna-se cada vez mais fundamental para que as empresas sobrevivam e, consequentemente, se tornem mais competitivas (Pellizzoni e Fialho, 2015). A descoberta e o desenvolvimento de produtos e serviços que venham a fazer com que as empresas alcancem lucro, crescimento, exposição e até mesmo a sobrevivência, fazem com que empresas se desafiem cada vez mais, procurem ir além e busquem soluções que, por vezes, transcendam a forma tradicional e conservadora de como vinham desenvolvendo seus produtos e negócios (Prahalad e Ramaswany, 2004).

A inovação faz parte da filosofia corporativa da empresa, que por mais de 70 anos, como citado, tem se diferenciado das demais presentes no mercado em que hoje está inserida. Com este espírito empreendedor, a empresa inaugurou o serviço Gestão de Frotas no mercado brasileiro no início de 2008, tendo-o implementado efetivamente em 2010, com o desejo de oferecer a seus clientes algo que viesse a quebrar paradigmas impostos pelos modelos tradicionais de uso de ferramentas elétricas.

Nos períodos de 2008 e 2009, o serviço foi usado por um pequeno número de clientes a fim de conhecer e entender mais sobre o mercado, o serviço, as vantagens, desvantagens e oportunidades de melhorias. Porém, foi somente em 2010 que o serviço alcançou notoriedade no mercado e foi de fato implementado, podendo-se a partir daí analisar os resultados de sua performance junto ao mercado brasileiro.

Antes de ser iniciado no Brasil, o serviço já havia sido implementado na Europa e EUA. Nestes mercados, a implantação foi favorecida devido a barreiras comerciais internas menos complexas e ao alto nível dos profissionais que buscavam serviços inovadores. Isso possibilitou à empresa alcançar consistentes resultados logo nos primeiros anos. No Brasil, por outro lado, as complexas e elevadas taxas tributárias, o baixo nível dos profissionais e sua cultura em obter a propriedade da ferramenta, eram obstáculos factíveis para que a gestão da companhia na ocasião receasse a implementação do serviço no Brasil. Porém, um estudo mais aprofundado do mercado e do profissional brasileiro levou a empresa a identificar várias oportunidades e a encorajou a prosseguir confiante. Por muitas vezes, estes profissionais e as companhias ficavam sem suas ferramentas nos momentos em que mais necessitavam de produtividade, por conta de consecutivas paradas dos equipamentos para manutenção ou também em razão de sinistros, levando ao atraso na execução dos serviços. O mercado da construção trabalha com metas e prazos limitadíssimos e o não cumprimento dos mesmos acarreta às empresas prejuízos elevados. 
Em estudos feitos com os principais clientes, observou-se que eles não se preocupavam com a gestão do parque de ferramentas, que corresponde a uma pequena parcela dos gastos, atentando-se somente para questões voltadas a curvas abc e custos com pessoal. Na Figura 1, pode se observar que as ferramentas elétricas representam de 2,0 a 5,0\% dos desembolsos dos clientes (constituídos principalmente por construtoras). Já o custo com pessoal fica normalmente entre 40 e $60 \%$, sendo os $35 \%$ restantes correspondentes a despesas com outros fornecedores.

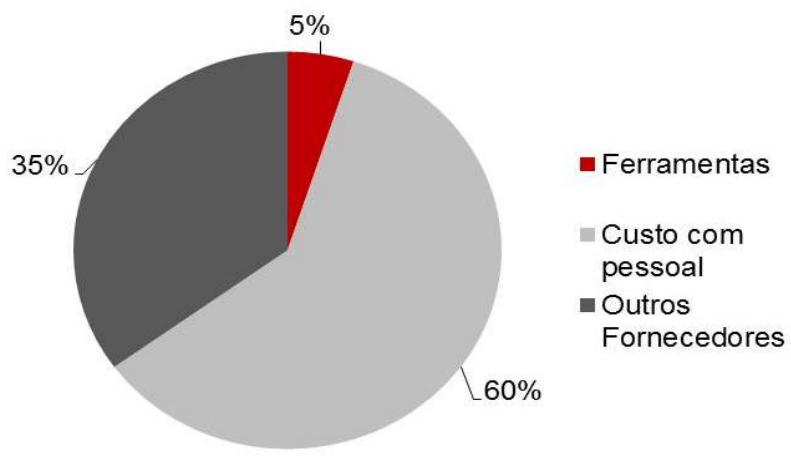

Figura 1. Percentual de custos desembolsados pelos clientes da empresa Fonte: Resultados originais da pesquisa

Verificou-se que, embora o cliente possuísse um parque de ferramentas próprio, não havia uma gestão eficiente do mesmo, o que omitia os verdadeiros valores desembolsados com a manutenção das ferramentas. O cliente, então, foi desafiado a apurar os custos que tinham para manter o parque de ferramentas, constatando-se, por conseguinte, que eram consideravelmente elevados.

A partir do levantamento dos custos com a propriedade da ferramenta, os quais englobavam custos de aquisição, reparação e administração, foi possível comparar os custos que o cliente teria se optasse pelo serviço Gestão de Frotas. Na Figura 2, verifica-se que os custos com o serviço estariam entre 50 e $80 \%$ dos custos referentes à propriedade. Desta forma, o parque de ferramentas via Gestão de Frotas se mostrava muito mais econômico.

Com isso, a empresa pôde obter informações claras de que as necessidades dos clientes não estavam na propriedade da ferramenta, mas sim na sua utilização, sem paradas ou interrupções das funções que executam. Isso a levou a identificar que o pagamento pelo uso e não pela propriedade seria muito mais eficiente, oferecendo ao usuário a liberdade de parar de se preocupar com custos, administração e outros fatos inerentes ao cuidado em manter um parque de ferramentas produtivo. 


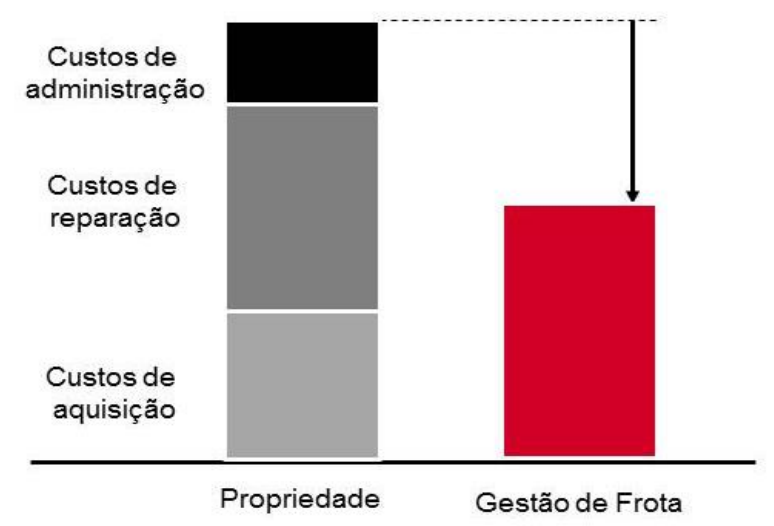

Figura 2. Custos com a propriedade das ferramentas em relação aos custos com o serviço Gestão de Frotas

Fonte: Resultados originais da pesquisa

É importante salientar que não é qualquer cliente que pode obter vantagens com o serviço e isso foi um ponto que a empresa pôde identificar após observações e análises no período inicial. Foi verificado que o serviço Gestão de Frotas não atenderia a todos os tipos de clientes, pois aqueles com perfil de baixo uso de ferramentas elétricas, e em ocasiões pontuais, não teriam suas necessidades atendidas, e neste caso, a aquisição dos equipamentos seria mais viável para eles. Ao contrário, aqueles que apresentavam grande demanda por uso contínuo de ferramentas se beneficiariam da utilização do serviço. A empresa identificou que clientes com perfil de baixo uso que contratavam o serviço Gestão de Frotas acabavam por devolver o equipamento contratado muito antes do prazo final negociado para a devolução. A devolução antecipada gerava prejuízos tanto para o cliente, que teria que arcar com as multas pelo não cumprimento do contrato, como para a empresa, que receberia um equipamento que não poderia ser mais comercializado. Este tipo de situação gerava ao cliente certa insatisfação, pois estava pagando por um serviço que não utilizava. Esse desgaste entre o cliente e a empresa pôde posteriormente ser evitado ao identificar no ato da negociação o correto perfil.

\section{Criação e apresentação da proposta de valor}

Segundo Osterwalder (2014), proposta de valor pode ser entendida como um conjunto de produtos e serviços que criam valor para um segmento específico de clientes. E pode-se acrescentar que o valor representa os benefícios entregues pela empresa a partir de uma relação direta na forma como os produtos e serviços foram oferecidos para atender às necessidades dos clientes internos e externos. A proposta 
de valor apresenta a forma como a marca se diferencia dos seus concorrentes, o que faz com que os clientes comprem seus produtos e serviços e não o de outras marcas que venham a ofertar algo parecido.

A proposta de valor para a criação do serviço Gestão de Frotas foi gerada tendo como base uma pesquisa realizada pela empresa junto aos clientes consumidores. A partir dessa pesquisa, constatou-se que os principais pontos ressaltados pela maior parte dos clientes relacionavam-se ao alto investimento para aquisição de ferramentas, aos custos com manutenção, à quebra dos equipamentos associados à falta dos mesmos nos momentos de pico, além de atividades administrativas para o gerenciamento do parque de ferramentas.

Estes pontos são considerados relevantes para que o cliente tenha uma boa produtividade e consiga entregar o serviço no prazo. Amparada nas informações levantadas, a empresa desenvolveu sua proposta de valor com vistas a atender a cada uma das expectativas anteriormente citadas. A Figura 3 ilustra os pilares da criação da proposta de valor, permitindo-se observar a empresa de um lado, oferecendo um serviço que pode remediar os problemas enfrentados pelos clientes, além de proporcionar-lhes uma série de benefícios (ganhos). Do outro lado, encontram-se os clientes necessitando realizar suas tarefas, que por sua vez culminam em uma série de adversidades (dores), as quais, no entanto, podem ser superadas com a utilização do serviço Gestão de Frotas, gerando vantagens (ganhos) aos clientes.

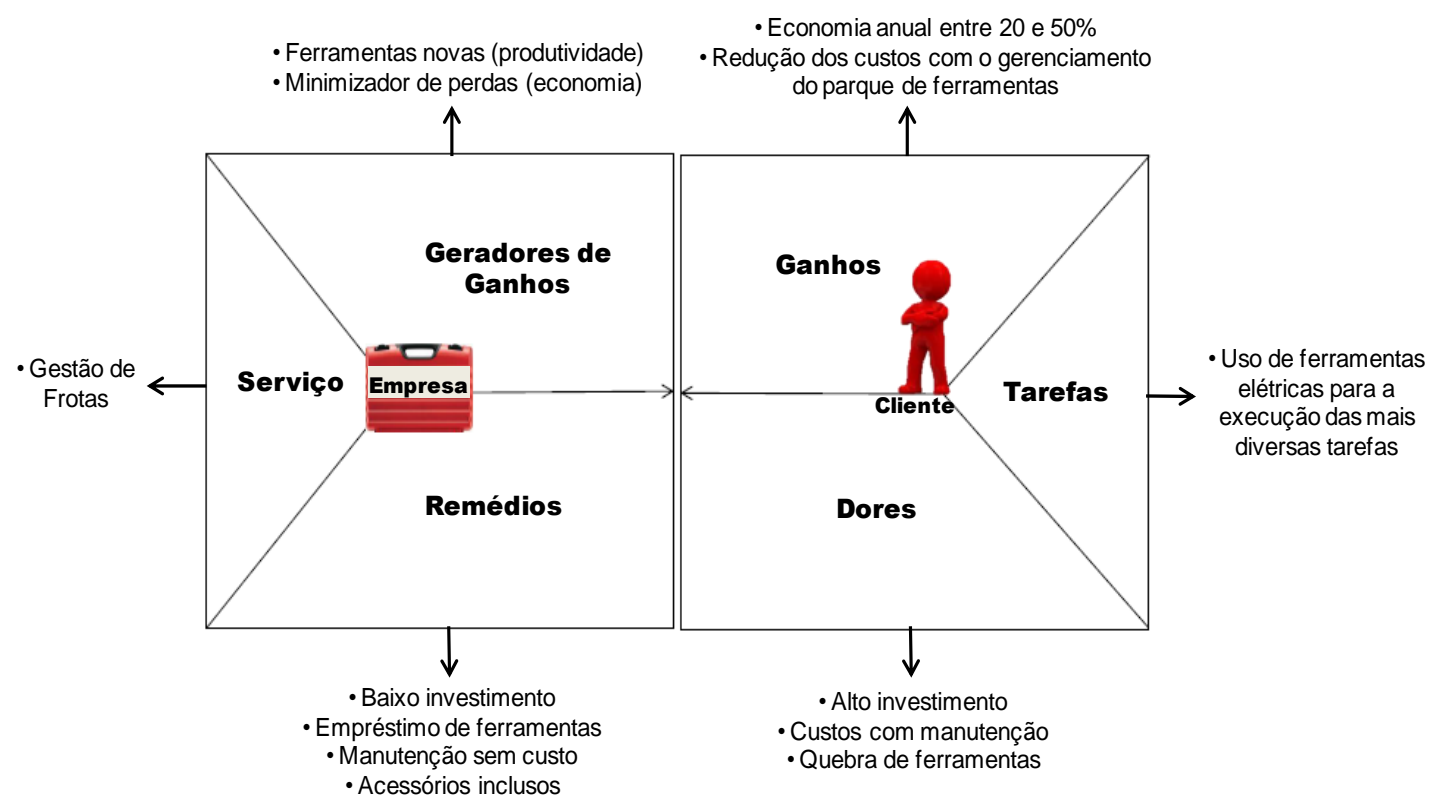

Figura 3. Base da criação da proposta de valor do serviço Gestão de Frotas Fonte: Adaptação ao modelo Canvas de Proposta de Valor (Osterwalder, 2012) 
Criar uma proposta de valor que atenda às necessidades dos clientes pode ser na maioria das vezes complicado. Desta forma, é fundamental que se conheça muito bem o negócio e o perfil do cliente para que a proposta de valor atenda a todas as suas expectativas.

Desenvolver uma proposta de valor onde o foco não estivesse na venda de um determinado produto e sim no seu uso foi o grande diferencial da proposta de valor criada pela empresa, ou seja, uma estratégia de marketing baseada na oferta de serviços e não na venda de produtos, abrindo novos caminhos para a inovação e criação de valor.

A noção de valor pode ser entendida como uma análise de custo-benefício referente a um produto (Holbrook, 1994; Zeithaml, 1988). Trata-se de uma comparação entre os benefícios obtidos com o produto e o serviço. Dessa forma, não é a aquisição de um produto que satisfaz o consumidor, mas sim o consumo real do mesmo. Isto sustenta a noção de que a transferência da propriedade de bens entre o consumidor e a empresa não é mais necessária. Com isso, a abordagem muda de uma estratégia baseada na aquisição para outra, orientada para o uso.

A partir desta perspectiva, a economia está de acordo com a lógica dominante do serviço. De fato, como o consumidor é percebido como um usuário de valor, a empresa faz propostas de valor que àquele pode adotar quando necessário (Vargo e Lusch, 2004). Esta convergência em torno da noção de valor em uso gera uma maior proximidade entre o produtor e o consumidor, ressaltando a mudança de marketing orientado para o relacionamento versus transação (Vargo e Lusch, 2004).

A criação de valor é central para o desenvolvimento de uma oferta. Em uma abordagem tradicional baseada na troca, o valor é medido de acordo com os custos visíveis do ponto de vista do cliente. A abordagem funcional vê valor de forma diferente e de um modo mais amplo, uma vez que considera outros parâmetros na sua avaliação, tais como custos ocultos e ganhos potenciais relacionados ao desempenho. No caso da empresa em questão, o valor em uso das ferramentas colocadas à disposição dos clientes só é gerado uma vez que estes tenham concluído o trabalho executado pela ferramenta.

Como explicado por Vargo e Lusch (2004), em vez de entregar o valor, a empresa oferece propostas de valor. Ao fornecer ao cliente uma utilização específica, sempre que necessária, a abordagem orientada para o uso pode influenciar o processo de criação de valor para o cliente, direta e ativamente (Grönroos, 2011; Saarijärvi, 2012). No extremo oposto, quando uma empresa tradicional vende um 
produto fabricado para seus clientes, proporciona uma simples promessa de valor e é o consumidor, influenciado pela empresa, que determina se a promessa foi cumprida ou não.

A proposta de valor do serviço Gestão de Frotas da empresa foi reconhecida pelos clientes, evidenciando-se que mais que o simples uso das ferramentas, o serviço oferecia canais de suporte, excelência operacional, economia com o gerenciamento do parque de ferramentas, além de se ter à disposição os melhores produtos do mercado e o contato com uma empresa de marca premium mundial (Figura 4).

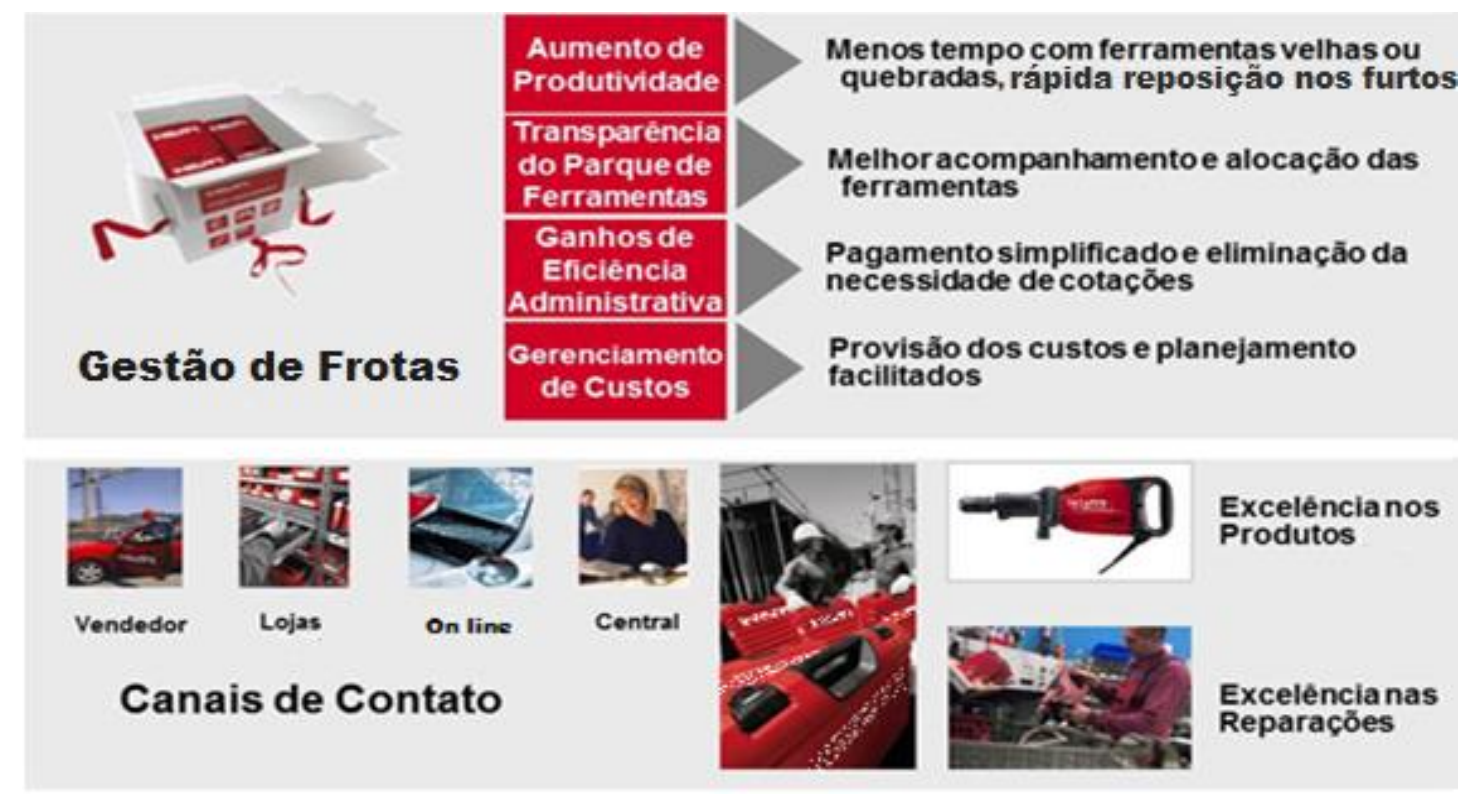

Figura 4. Proposta de valor do serviço Gestão de Frotas

Fonte: Resultados originais da pesquisa

A proximidade entre a empresa e seus clientes fortalece suas relações, as quais se tornam um aspecto fundamental da prestação de serviço (Grönroos, 2011; Saarijärvi, 2012). Essas interações envolvem diversos processos dialógicos que convergem em um único processo de ações coordenadas em que ambas as partes se envolvem ativamente, aprendem e influenciam umas às outras (Ballantyne e Varey, 2006). A partir de um relacionamento mais estreito com seus clientes, a empresa foi capaz de aprender com eles e identificar suas reais necessidades, proporcionandoIhes um melhor serviço. Ao mesmo passo, os clientes também puderam se beneficiar com o serviço e com a experiência da empresa. 


\section{Benefícios proporcionados pelo serviço}

O reconhecimento do serviço levou a empresa a alcançar grandes benefícios junto aos clientes e ao mercado de atuação. A aproximação com os clientes possibilitou à empresa obter um conhecimento mais profundo dos processos decisórios que os levam a consumir produtos e serviços semelhantes ofertados no mercado. Com isso, a empresa pôde se antecipar e ter uma resposta mais rápida e assertiva para a venda de seus produtos e, principalmente, para a apresentação do serviço Gestão de Frotas. Isto gerou, no primeiro ano de implementação, em 2010, um incremento significativo no percentual de ferramentas negociadas via Gestão de Frotas, cerca de $20 \%$ (Figura 5), surpreendendo a companhia que, ao contrário, esperava algo em torno de $10 \%$ inicialmente. O serviço continuou com índices de crescimento consideráveis nos anos subsequentes, alcançando seu auge em 2015, no qual $52 \%$ do total de ferramentas negociadas foram via Gestão de Frotas, número bem expressivo, levando o serviço a ganhar relevante atenção dentro da companhia.

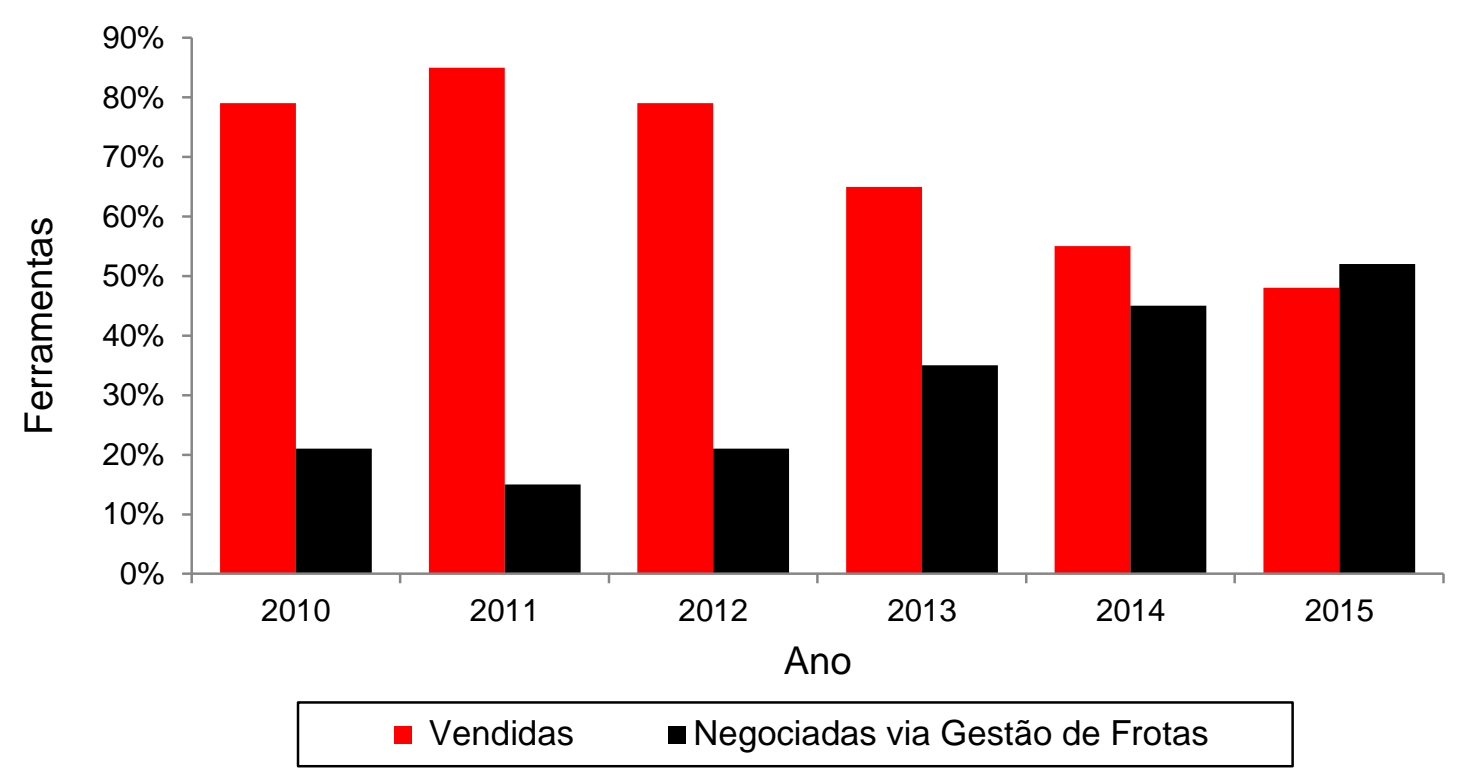

Figura 5. Comparação do percentual de ferramentas elétricas vendidas em relação ao de ferramentas negociadas via Gestão de Frotas no período de 2010 a 2015 Fonte: Resultados originais da pesquisa

Na maioria dos contratos iniciais, os clientes iniciavam suas experiências com o serviço de forma tímida, apenas com um número bem limitado de ferramentas e geralmente com aquelas de menor valor mensal. Ao longo do contrato foram adicionando novas unidades e modelos, os quais não costumavam utilizar por conta do alto custo ou até mesmo por desconhecimento da gama de ferramentas 
disponíveis. Com isso, a empresa obteve um aumento significativo na penetração do mix de produtos e portas foram se abrindo para que todo o seu portfólio fosse mostrado. No entanto, isso não aconteceu apenas com novos clientes. Aqueles já fidelizados passaram a utilizar o serviço, o que fez aumentar o relacionamento, confiabilidade e exposição da marca junto ao mercado consumidor.

A Figura 6 ilustra o percentual de novos contratos e de ferramentas negociadas via Gestão de Frotas no decorrer do período analisado. Em 2010, ano de início do serviço, a empresa alcançou um crescimento de $64 \%$ em relação à meta inicial estabelecida para as ferramentas e um aumento de $2 \%$ para novos contratos. No auge das oportunidades oferecidas pelo mercado brasileiro, em 2013, a empresa obteve um recorde com um crescimento em mais de $80 \%$ para novos contratos. E em 2015, o número de ferramentas negociadas aumentou em 114\% em relação ao ano anterior. No início do serviço, a média de ferramentas por contrato estava em 13 unidades, já em 2015, essa margem se elevou para 23 unidades.

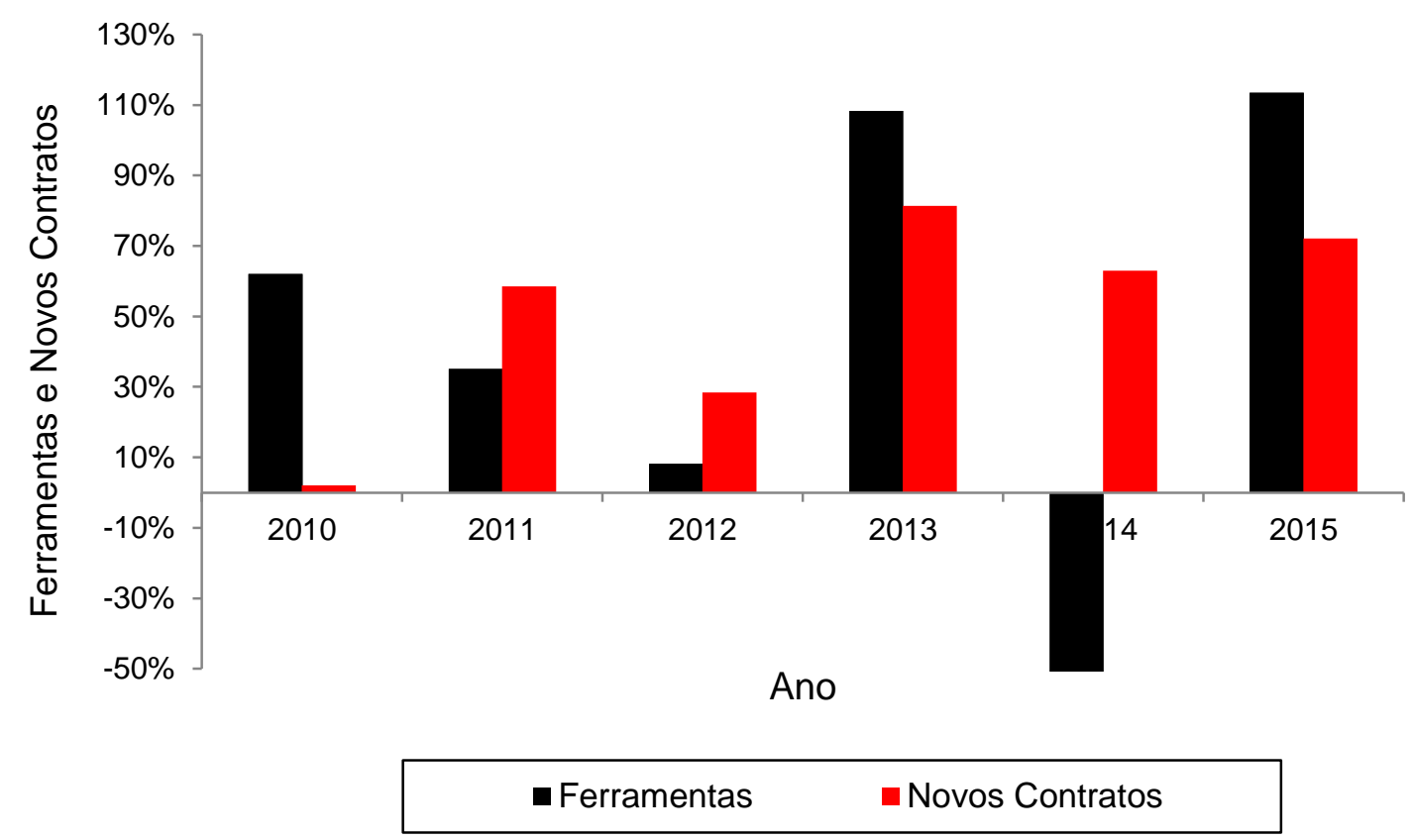

Figura 6. Percentual de novos contratos e de ferramentas negociadas via serviço Gestão de Frotas no período de 2010 a 2015

Fonte: Resultados originais da pesquisa

A partir da Figura 7, pode se ter uma visão geral dos recursos financeiros provenientes do serviço. Observa-se que a adição de novas ferramentas aos contratos já existentes constitui a maior fonte de renda oriunda do serviço variando de 55 a $72 \%$ no período analisado. Em seguida, encontra-se o fechamento de novos contratos, 
sendo responsável por aproximadamente um quarto dos recursos gerados. Por fim, verifica-se a renovação de contratos anteriores, apresentando uma média de $15 \%$ no período total.

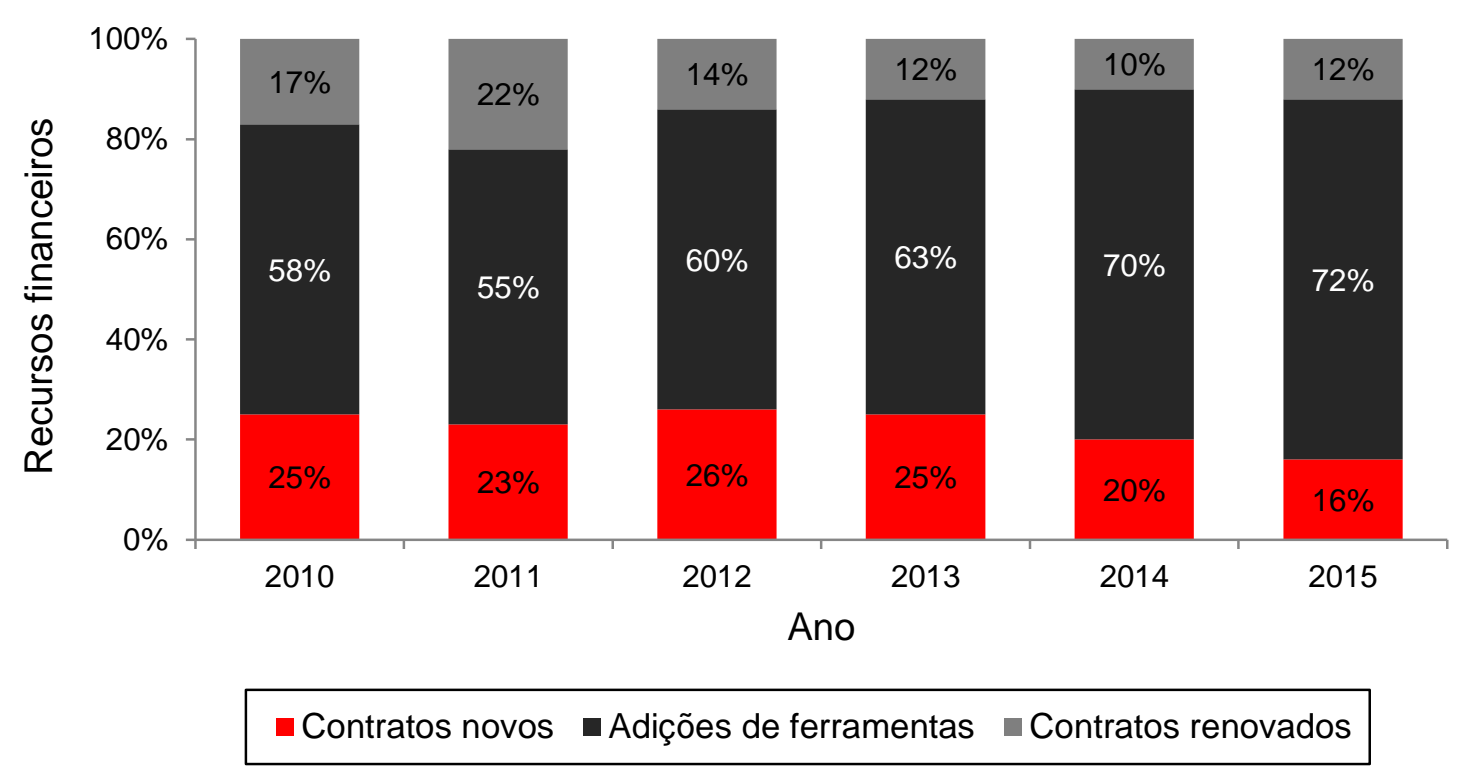

Figura 7. Visão geral do percentual de recursos financeiros oriundos do serviço Gestão de Frotas no período de 2010 a 2015

Fonte: Resultados originais da pesquisa

Além disso, o desenvolvimento do serviço levou a empresa a ter um aumento significativo também nas vendas dos insumos utilizados pelos equipamentos. Por conta disso, a companhia foi incentivada a investir no desenvolvimento de novos consumíveis que viessem a integrar o portfólio de produtos. O serviço de excelência, ligado a um excelente equipamento e ao uso dos consumíveis corretos, levou os clientes a utilizarem não apenas uma linha de produtos, mas também outras. Atualmente, a média de consumo é de cinco linhas de produtos por cliente.

Em suma, pode-se destacar que o serviço Gestão de Frotas trouxe muitos benefícios à empresa como lucratividade, "market share" e mix de produtos. Estes são contáveis, mas as incontáveis e incalculáveis contribuições que este serviço pôde proporcionar são muitas como a proximidade com o cliente, a confiança, o engajamento e também o aumento da exposição da marca, que atualmente está presente na maioria das obras de construção civil realizada no Brasil. 


\section{Conclusão}

A partir da análise realizada neste estudo, pode-se concluir que a empresa inicialmente identificou os aspectos que envolviam os problemas enfrentados pelos clientes em relação ao uso e gerenciamento das ferramentas utilizadas na execução de suas tarefas diárias na construção civil. A partir disso, conseguiu destacar oportunidades que poderiam trazer benefícios aos clientes e também a si mesma, identificando que a real necessidade não estaria na propriedade dos equipamentos, mas sim na sua utilização. Assim, criou uma proposta de valor que levasse o cliente à percepção de vantagens até então não identificadas por ele próprio, trazendo o conceito de que o pagamento pelo uso e não pela propriedade da ferramenta seria mais eficiente. Com isso, quebraram-se paradigmas, estabelecendo uma transição da aquisição do equipamento para a sua utilização, mediante o serviço Gestão de Frotas. Os impactos desse serviço são expressivos, proporcionando maior engajamento, proximidade e estreitamento das relações com os clientes e promovendo maior exposição da marca junto ao mercado de ferramentas elétricas, aumentando as vendas e a lucratividade da empresa.

Como o trabalho foi realizado através do método de estudo de caso, os resultados limitam-se à empresa, não sendo cabíveis generalizações, porém muitos "insights" podem ser proporcionados para a gestão de negócios de outras companhias.

\section{Agradecimento}

À empresa em estudo, por liberar as informações e os dados necessários para a realização deste trabalho.

\section{Referências}

Ballantyne, D.; Varey, R.J. 2006. Creating value-in-use through marketing interaction: the exchange logic of relating, communicating and knowing. Marketing Theory 6(3): 335-348.

Drucker, P.F. 2002. Inovação e Espírito Empreendedor: Prática e Princípios. Pioneira, São Paulo, São Paulo, Brasil.

Grönroos, C. 2011. A service perspective on business relationships: the value creation, interaction and marketing interface. Industrial Marketing Management 4(2): 240-247.

Holbrook, M.B. 1994. The nature of customer value: an axiology of services in the consumption experience. p. 21-71. In: Rust, R.T.; Oliver, R.L. Quality: New Directions in Theory and Practice. Sage Publications, Thousand Oaks, California, USA. 
Mattos, P.L.C.L. 2005. A entrevista não-estruturada como forma de conversação: razões e sugestões para sua análise. Revista de Administração Pública 39(4): 823847.

Osterwalder, A. 2012. Achieve product - market fit with our brand-new value proposition designer canvas. Disponível em:

<http://businessmodelalchemist.com/blog/?month=august-2012\&view=calendar $>$. Acesso em: 15 out. 2016.

Osterwalder, A. 2014. Value Proposition Design. Wiley \& Sons, New Jersey, New Jersey, USA.

Pellizzoni, R.C.; Fialho, F.A.P. 2015. Inovação e design na trajetória de empresas longevas. Revista E-Tech: Tecnologias para Competitividade Industrial 8 (Edição Especial - Design): 107-118.

Prahalad, C.K.; Ramaswamy, V. 2004. O futuro da competição: como desenvolver diferenciais inovadores em parceria com os clientes. Tradução de Afonso Celso da Cunha Serra. Elsevier, Rio de Janeiro, Rio de Janeiro, Brasil.

Saarijärvi, H. 2012. The mechanisms of value co-creation. Journal of Strategic Marketing 20(5): 381-391.

Tidd, J.; Bessant, J. 2015. Gestão da Inovação. 5ed. Bookman, Porto Alegre, Rio Grande do Sul, Brasil.

Vargo, S.L.; Lusch, R.F. 2004. Evolving to a new dominant logic for marketing. Journal of Marketing 68: 1-17.

Ventura, M.M. 2007. O estudo de caso como modalidade de pesquisa. Revista SOCERJ 20(5): 383-386.

Yin, R.K. 2015. Estudo de Caso: Planejamento e Métodos. 5ed. Bookman, Porto Alegre, Rio Grande do Sul, Brasil.

Zeithaml, V.A. 1988. Consumer perceptions of price, quality, and value: a means-end model and synthesis of evidence. Journal of Marketing 52(3): 2-22. 